\title{
Modern Shipping Navigation based on Telemetry and Communication Systems
}

\author{
M. Papoutsidakis \\ Dept. of Automation \\ Engineering \\ PUAS, Athens, Greece
}

\author{
E. Symeonaki \\ Dept. of Automation \\ Engineering \\ PUAS, Athens, Greece
}

\author{
D. Piromalis \\ Dept. of Automation \\ Engineering \\ PUAS, Athens, Greece
}

\author{
D. Tseles \\ Dept. of Automation \\ Engineering \\ PUAS, Athens, Greece
}

\begin{abstract}
This project deals with one of the most critical sectors in the maritime industry and specifically to telecommunications through which is a comprehensive presentation and analytical study of systems and applications falling in this area. Initially a brief introduction on the industry and then an overview of the requirements that satisfy the services offered by telecommunications and the rapid improvement of electronic communication systems over the years. In the second chapter we analyse the basic principles of operation of nautical electronic navigational appliances and marine research, their characteristics and ways of using them. Following is a detailed presentation of satellite systems since become initially grasp the context of the regulations as mandatory through SOLAS developed by the IMO. Finally, the fourth chapter classifies the electronic applications of the shipping office according to their field of use. The formats presented vary, but can be divided into two main categories: office and ship applications, which work complementarily by exchanging data and information.
\end{abstract}

\section{Keywords}

Shipping Navigation

\section{INTRODUCTION}

The substantial development of technology in the department of shipping, in combination with the need for valid and direct information, set the Information Systems one of the most necessary tool in the field of shipping. The practices of Information Systems are constantly increasing, as the shipowners and executives' demands are in a high rate. This survey examines the necessity of Information Systems' utility in the Greek maritime industry. The amplitude of these systems is so substantial similar to the requirements of the businesses. It's going to be analyzed the most basic and common I.S which are in a great use in Greek shipping. Our purpose in this survey is to explicate these systems and make a reference about its advantages and disadvantages simultaneously.

It's a common admission that communication has a significant role in marine. The ship needs to communicate and interact with the land and the other ships. For centuries, there was a lack of direct and trustworthy communication among two parts.

However, accidents and tragedies that occurred and convulsed the entire world rendered the utility of wireless communication an imperative solution.

While continuous changes were occurred in international treaty SOLAS, in 1st February 1992 was adopted the use of Global Maritime Distress and Safety System (GMDSS). This system includes terrestrial and satellite subsystems. Of course, the wireless communication facilitated the life of seafarers. Furthermore, the contact capabilities and the exchanges of information with the shore and the other ships augmented the safety of human life in the sea, while at the same time ensured both, personal and professional needs. The communication among the ships and the shore has a prerequisite. the existence of specific systems inside the ships, which through the stations existing in the shore and through the satellites, repeat the marks. While the communication between the ships can be performed by VHF with the Digital Selective Call (DSC) which, through digital commands, transmits or receives signs of danger, emergency signs, safety signs, routine messages or priority messages. Moreover, the communication between the ships - for long distances- can be achieved by MF (middle waves) and HF (short waves). The auditors DSC can be incorporated with the radio VHF according to SOLAS.

\section{CHARACTERISTICS OF MARITIME INDUSTRY}

The separation of markets in maritime industry is based on:

- The type of cargo

- The geographic area

- The demands of the sea routes

- The type of the ship

The Maritime Industry, based on the type of carried cargo, is divided into the following categories:

- Passenger Shipping

- Shipping of raw materials and commodities (liquid cargo, dry cargo, containers, e.c.t. )

The Maritime Industry, based on the sea routes, is divided into the following categories:

- $\quad$ Ponto pore Shipping

- Short distance Shipping

Bulk and liner Shipping

We can distinguish, according to Stopford, two different Shipping Markets. Bulk Shipping and Liner Shipping, which, in reality, are governed of the two different types of the carrying cargo Bulk cargo and General cargo.

Bulk Cargo

The quantity of the lot to be transported is so large that can supplement the tonnage of a ship. (4 categories):
i. Liquid bulks (crude oil, chemically, e.c.t.)
ii. The Five major bulks (anthrax, cereals, iron ore, e.c.t.)
iii. Minor bulks (steel, timber, salt, aluminum products, e.c.t.)
iv. Dry cargoes

General Cargo

The quantity of the lot to be transported is not enough to supplement the tonnage of a ship. 


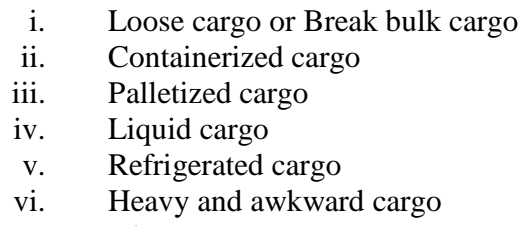

The maritime industry in Greece

The two out of four as the main and the only activity is the General Cargo and the third one has the Bulk Cargo. The fourth maritime is engaged in more activities, as it is one out of the five biggest Maritimes in Greece. Her activities include:

\begin{tabular}{ll}
- & Bulk Dry Cargo \\
- & Bulk liquid Cargo \\
- & Lings \\
- & Rings \\
\hline & Drill Ships
\end{tabular}

Navigational electronic instruments-Radar navigation device Radar navigation is a device which aims to detect targets that are found on the surface on the sea or at a small height from it.

Basic parts of the Radar

Radars consist of the following five functional parts:
a. The antenna
b. The transmitter
c. The receiver
d. The transmit-receive switch
e. The indicator

Gyrocompass

The gyroscope is a solid body that can rotate around an axle crossing from its center of gravity.

\section{Constructions requirements}

1. Appropriate support and power supply

2. Appropriate power supply of electrical components connected to the main unit

3. A suitable search and stabilization system for one end of the axis of rotation

4. A suitable system with which the part 000-180 can watch the direction of the axis of the gyroscope

5. A suitable transmission system

6. For each of the above units. for the main unit bell displays in the various repeaters.

7. And finally, appropriate support system

The free gyroscope and its properties

The free gyroscope consists of a rotting mass (flywheel or Gyrosferon). Gyrosferon can move freely around three axes:

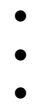
Around its axis of rotation

$\bullet$

Around the horizontal axis

- $\quad$ Around the vertical axis

\section{Operating principle}

A significant implement of gyroscope is the gyrocompass, a device that is used to find the orientation on the ships. The errors presented by the gyrocompass are:

1. The track width and speed error

2. The damping error

3. The Ballistic defeat error

ECDIS

4. The ship's failure error

The systems of electronic map are called Electronic Chart Display and Information System.

Elaboration of specifications:
- The primary mission of ECDIS is its contribution to the safe navigation

- The use of ECDIS is possible to be considered that is equivalent to shipper's obligation to use informing printed maps.

- Full implementation of all operations and procedures for the preparation, planning and execution of the sailing similar to traditional methods.

- Many additional features are provided that greatly reduce the load and the workload on the bridge.

ECDIS is a combination of many different shipping aids, devices and organs (electronic navigation maps, RADAR/ARPA, GPS, compass and fathometer) in a central screen from which is possible to fully monitor the voyages and adjust the readings, and further is provided the capability of taking direct and correct decisions.

\section{Satellite tracking systems}

The determination of the position of a point has been greatly improved with the development of satellite tracking systems. In these systems are being used electromagnetic signals emitted by satellites which rotate in orbits around the earth. The satellite signal is received by the receivers and, with the appropriate calculations, the co-ordinates of the points executed.

\section{Basic categories and main GPS features}

According to the internal structure and how they function, GPS receivers are classified into:

- Continuous or multichannel

- Multiplexers

- Sequencers

At hydrographic applications are using techniques of static or kinematic positioning, but they separate on:

a) The absolute kinematic positioning with GPS.

b) The relative position kinematics with GPS

\section{METHODOLOGY AND INSTRUMENTS}

Sound engineers - High frequency bottom tomography

These systems are based on the production of an electromagnetic sound pulse. The electromagnetic pulse is emitted and reflected in the bottom is obtained from a single system of transducers incorporated in the towing unit.

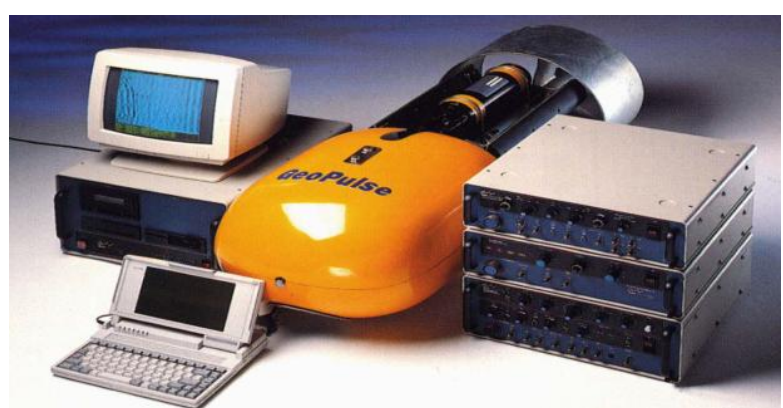

Fig.1 Complete high-frequency sound system $(3,5 \mathrm{~Hz})$ with submarine unit-transducers ("fish"), production and processing unit 


\section{Boomer systems (range of frequencies $0.5-10 \mathrm{kHz}$ )}

Boomer system is based on the production of a strong electromagnetic pulse from a metal plate that is placed on floats. On the other, the reception of the reflected sound waves is recorded by a short length of a series of hydrophones.

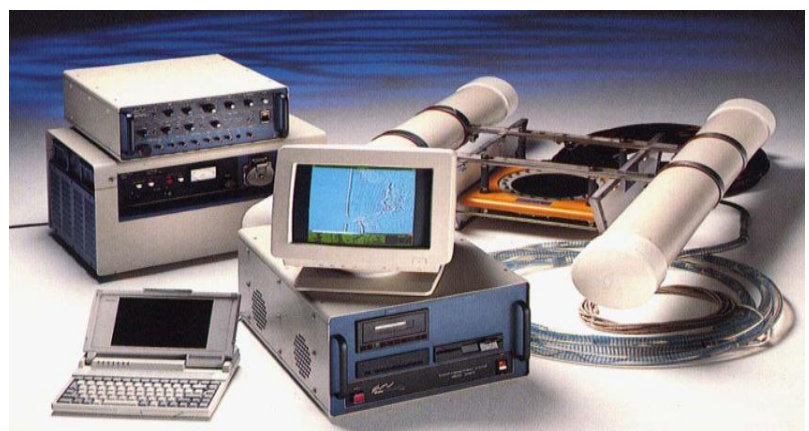

Fig. 2 A complete system Boomer with the production units-aid-signal processing, the hydrophones, transmitter's towing unit and the recorde.

Sparker systems (range of frequencies 0,1-1 kHz)

Sparker system is based on the emission of sound pulse from electric discharge through electrodes.

Air-Gun systems

(range of frequencies 0,05-0,8 kHz)

Side scan sonar

Side scan sonar is used to identify specific "targets" at the bottom (such as shipwreck, anchors, ancient ruins in scientific studies to determine the composition and configuration of the morphology of the bottom.

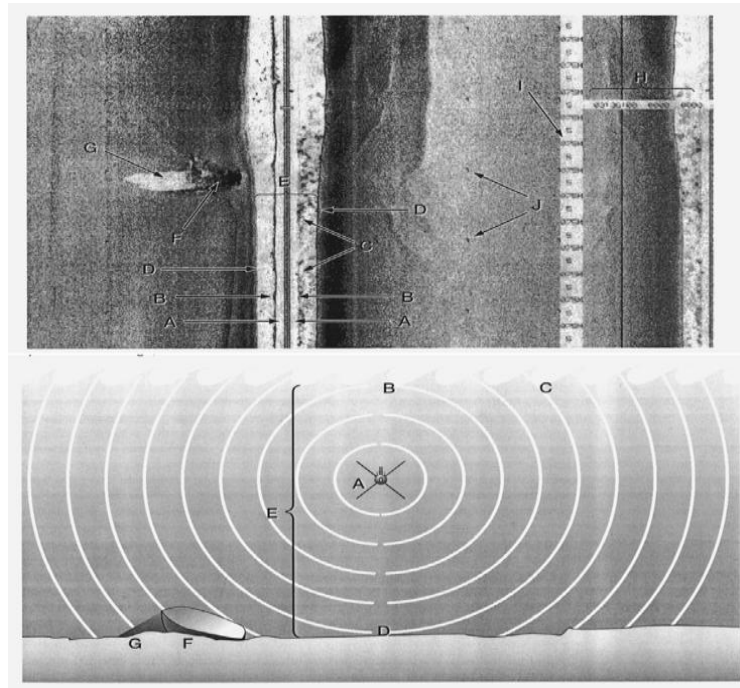

Fig. 3 Example of recording (above) and schematic interpretation of the basic operating principles (broadcasting and recording) of the Side scan sonar reflections (side sounding) (down). A: "Fish" position recording pulse transmission, B: first reflection of water surface, C: reflections of waves, D: first reflection cutting, E: water column area, F: immersed fishing, G: shadow, H,I: coding attribute codes, J: points of displacement (25m)

\section{CONTEMPORARY SATELLITE SYSTEMS}

Maritime telecommunication services

The most crucial role of telecommunication in the field of management sea-going ships is based on the telecommunicative infrastructure of the ship and is related not only to the cover of the general needs for communication, but also to the successful confrontation of emergency situations among ship and land and among the two ships as it is defined by the treaty SOLAS and the system GMDSS claims a framework of conventional services such as radio communication, two way telephony, fax, telex, messages and telex notification.

Framework of regulations about telecommunications

- Global Maritime Distress and Safety System GMDSS

- $\quad$ Automatic Identification System (AIS)

- $\quad$ Vessel Traffic Services (VTS)

- Vessel Traffic Management and Information System (VTMIS).

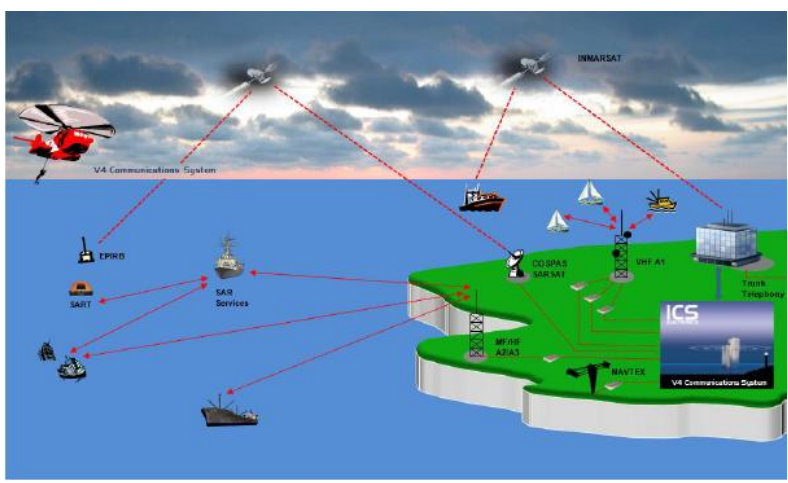

Fig 4 Typical communication network

Global Maritime Distress and Safety System

The global maritime distress and safety system GMDSS is a international agreement, which contains a number of instructions and procedures and protocols of communication that are used to increase the safety and to facilitate the rescue of the watercrafts or the aircrafts that are in danger.

\section{Automatic Identification System (AIS)}

The automatic identification system is an automatic detection and identification system of ships that broadcast via maritime frequency VHF. The purpose of that system is to ensure the ship's safety via the exchange of similar information between other ships and vessel tracking services stations.

The information that is broadcasted are categorized into:

- The number of international maritime organization, the international distinctive mark and name, the ship's style are included into the static information.

- The exactly position and the route of the ship, the exactly time UTC, the turning rate are included into the dynamic information.

- The draft, the kind of shipment and the destination of it are included into the navigation information. 
The types of function are:

1. Autonomous constant mode

2. Polling mode

3. Assignment mode

VTMIS-VTS

The acronym "VTMIS" stands for Vessel Traffic Management Information System. That system supervises the heading of ships.

The national system of VTMIS can be separated into entities as detailed below:

- Vessel Traffic services

- Regional Traffic Services

- $\quad$ Remote Site Sensors

- Relay Station

The National center VTMIS constitutes a valuable tool for the analysis and processing of traffic data. The communication between VTS and VTMIS is actualized by leased services of the telecommunication group in Greece. The national VTMIS system comprises 4 local vessel traffic services, 3 regional traffic services, 13 remote sites sensors, 5 relay stations, 1 VTMIS, a training room and a room for technical services.

The distinguishing features of the VTMIS are:

- Absolute harmonization with Global Organizations (IMO, IALA, ICAO, IEC, CIRM, ITU)

- Possible diffusion of information to interested parties ( Maritime Agencies, Coastguard)

- Combination of two or more sensors

- $\quad$ Spaced out and synchronized data processing

- High standards of credibility and availability

Inmarsat

1. The International Maritime Satellite determines the placement and maintenance of parallel satellites and the granting of the right to use them. The INMARSAT consists of 4 telecommunication satellites in a geostationary (or geosynchronous) orbit and is common to all INMARSAT systems. They are placed in the plane of the equator. They are used as radio repeaters.

There are a variety of types for ship stations, which determines the type of communication the ship can make through the corresponding INMARSAT system. The types of devices are as follows:

- INMARSAT B

- INMARSAT C

- $\quad$ FLEET 77

\section{Globalstar - Thuraya}

The mobile satellite Thuraya network is based on GEO satellites and covers 140 places in Europe, Middle East, central and North Africa and central Asia. The satellite calls are guided directly by a portable unit to another one or to a landed network.

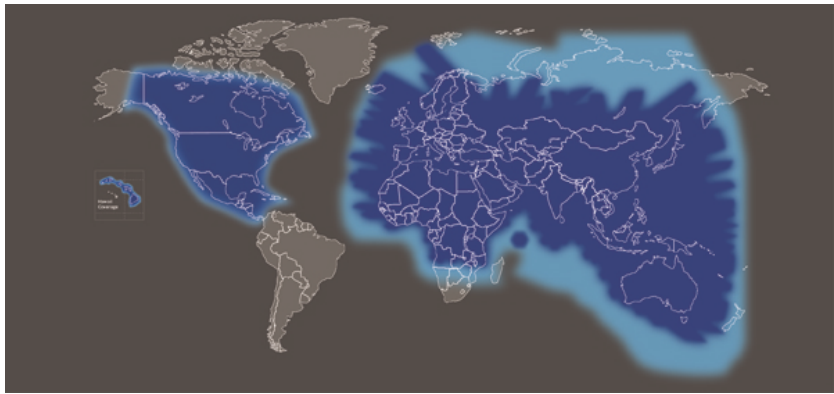

Fig. 5 Map of Thurayas' services

Iridium

The Iridium network uses 66 low satellites in earth's orbit (LEO). The provided services are the voice transmission, SMS and data between land- ship or ship-ship with $9.6 \mathrm{Kbps}$. One more service of Iridium system is the internet access.

VSAT

The "Very Small Aperture Terminal" is earthly stations with specific features that they can come into contact with other stations always with the help of satellites.

The VSAT consists of two parts:

- In Door Unit: It is placed at the user's workplace

- Out Door Unit: It is placed outdoors.

Nowadays the use of VSAT in the field of maritime is focused on coasting and crusing and it has two ambits.

- The integrated telecommunication platform ( Fax, voice transmission, Internet access, Fleet Management, Maintenance Logistics, E-Learning, Operations monitoring).

- The geographic extension of the GSM cover.

Electronic applications of a shipping office

As we all know, the core of shipping is the ship. So, if in any other industry the right flow of information has a significant role, in shipping is much bigger. The systems that connect the office with the ship present a significant progress as the administrative firms increase the degree of computerization and networking between its parts with the ship.

The seven basic categories of the offered products/services depending on usage are:

- Communication software

- Technical monitoring and maintenance of the ship

- Quality and safety management systems

- Inventory control

- Electronic supplies / orders

- Operations/ voyage management

- Human resources-crew management

Depending on how they work and use, we can distinguish:

- Integrated systems

- $\quad$ Electronic shipping markets 


\section{CONCLUSIONS}

Considering that Shipping accounts for almost $96 \%$ of the transport industry, one can understands why it is driving the global economy. The global legislative framework is constantly evolving, taking account the industry's circumstances as they are shaped by the day-to-day activity of ships and shipping companies and the findings of exploring all marine casualties.

Therefore, continued adaptation of shipping to changing conditions along with the development of its infrastructures and the improvement of the efficiency and quality of the offered services are necessary.

With regard to existing satellite services, a set of alternative services to satellite telecommunications is now available in addition to the main player Inmarsat. Iridium and Globalstar have competing products in voice services, while VSAT systems already offer broadband connectivity to the ship.

Furthermore, there are systems based on regional geostationary satellites such as Thuraya, combined with terrestrial mobile telephony systems that are a cheaper alternative for some specific geographic areas.

Nowadays, the choice of the appropriate service depends on the specific needs of the user, the cost of use and the equipment. Satellite telecoms have evolved over the last few years at a rapid pace, resulting in the development of new technologies that are going to offer broadband connections to shipping.

By adopting electronic applications and services, as discussed above, shipping can have tremendous benefits such as finance, safety and environmental protection. Managing information over the network is easier with modern services. In the field of information and communication technology solutions, investments in a substantial part of the Greek-owned shipping are underdeveloped, with the result that the extensive support of business processes has not yet been achieved.

The main obstacles to further adoption of e-services and solutions, according to shipping companies, are summarized in the initial cost of installation, the lack of reliability and effective technical support, the high cost to date of existing satellite telecommunication services, the lack of compatibility with an existing framework Procedures and the lack of standards in digital forms that limits the benefits to shipping companies from the adoption of e- solutions and will allow the development of integrated solutions. However, each company's business planning plays an important role in the adoption of new technologies.

\section{ACKNOWLEGDEMENTS}

All authors would like to express their gratitude to the Piraeus University of Applied Sciences for providing the required data and funding in order to undertake and complete this research project as part of "Industrial Automation" Postgraduate Program of Studies.

\section{REFERENCES}

[1] R.-E. King, Information control, Athens: Papasotiriou Edition, 1994.

[2] R.-E. King, Industrial Informatics, Salonica: Tziolas Edition, 2014.

[3] A. Veloni and St. Alatsathianos, Industrial Informatics, self publishing, 2014.

[4] St. Manesis, Industrial Network PLC, Patra: Patra University Press, 2007.

[5] St. Manesis, Industrial Automation System, Patra: Patra University Press,2006.

[6] R.-E. King, Measurements system, Salonica: Tziola Edition, 2001.

[7] R.-E. King, AI in control, Athens: Traulos Edition, 1998.

[8] M.J. Shaw, Information - Based Manufacturing, USA: Kluwer Academic Publishers, 2001.

[9] Chr. Lykos, Shipping Telemetry System, Thesis, ¿HMMY, ЕMП, 2007.

[10] Melone, N. 1990. A theoretical assessment of the usersatisfaction construct in information systems research. Management Sci. 36(1) 76-91.

[11] Seddon, P. 1997. A respecification and extension of the DeLone and McLean model of IS success. Inform. Systems Res. 8(3) 240-253.

[12] Davis, F. D., R. P. Bagozzi, P. R. Warshaw. 1989. User acceptance of computer technology: A comparison of two theoretical models. Management Sci. 35(8) 9821003.

[13] Davis, Fred D. (1993). User Acceptance of Information Technology: System 